\title{
Particle Characterization of Bamboo Leaves Charcoal Resulted by Ball Milling
}

\author{
Supriyono $^{1 *}$, Yoyo Saputro ${ }^{1}$, Ngafwan $^{1}$, Wijianto $^{1}$, Waluyo Adi Siswanto ${ }^{1}$, Muhammad Sukri Mustapa ${ }^{2}$ \\ ${ }^{1}$ Department of Mechanical Engineering, Universitas Muhammadiyah Surakarta, Surakarta 57102, Indonesia \\ ${ }^{2}$ Faculty of Mechanical and Manufacturing Engineering, Universiti Tun Hussein Onn Malaysia, Parit Raja 86400, Malaysia
}

Corresponding Author Email: supriyono@ums.ac.id

https://doi.org/10.18280/acsm.440110

Received: 7 November 2019

Accepted: 21 December 2019

\section{Keywords:}

charcoal, bamboo leaves charcoal, ball milling, particle characterization, particle size analyzer, particle morphology

\begin{abstract}
The aim of this work is to characterize particle of bamboo leaves charcoal produced by ball milling process. The characterization parameter are the particle size and the morphology of the particle. The milling process was completed in a cylinder vial made from stainless steel. The milling element was a steel ball. The dimension of the cylinder vial was $120 \mathrm{~mm}$ length and 1 inch diameter, while the ball diameter was $0.25 \mathrm{inch}$. The charcoal was crushed manually then sieved with a filter size of 200 meshes. The particles passing the filter were then put together with the milling balls into cylinder vial. The cylinder vial was shaken to have ball collision for the size reduction. The shaker machine was operated at $1000 \mathrm{rpm}$ for 2 million cycles. The empty space in the vial was varied for $1 / 2,1 / 3,1 / 4$ and 1/5 empty space of vial volume. Further work is done to see the effect of the machine speed to the characteristics of particles. The machine is operated at $800 \mathrm{rpm}, 900 \mathrm{rpm}, 1100 \mathrm{rpm}$ for $1 / 5$ empty space and 0.25 inch ball diameter. Particle size analyzer (PSA) was used to measure average particle size, while Scanning electron microscope (SEM) and Energy Dispersive X-ray (EDX) were employed to see the particle morphology and the content of elements in the bamboo leaf charcoal. The results showed that the average size of particles is in the range of $300 \mathrm{~nm}$ to $600 \mathrm{~nm}$. There is no certain relationship between final particle size and percentage of vial volume empty space. The SEM results showed that the particle shape is irregular as a result of fracture due to collision. The most dominant element is carbon which is more than $60 \%$ and the second is silicon dioxide (silica) which is more the $20 \%$.
\end{abstract}

\section{INTRODUCTION}

Bamboo is a fast-growing plant which is in Ordo Bambooidae. It can be harvested at the age of 3 years and the production is about 33.4 to 109.2 tons per ha per year [1]. Indonesia has a lot of bamboo. It can be found easily in Java, Bali, Sumatera, and south Sulawesi [2]. A lot of use of Bamboo results in a lot of waste material as well. One of the waste materials is bamboo leaves. According to Amu and Adetuberu [3], bamboo leaves have high silica content after carbon. Silica in nano scale is more effective in promoting the growth and development of crop plants [4, 5].

Numerous journal studies can be found to examine the properties and the effective applications of the bamboo fibers. The properties of bamboos are reported recently by Xu et al. [6], Tanpichai et al. [7] and Hai et al. [8], while the application is of the bamboo on the structure [9-11] and related fabrication of bamboo fibers are publicly revealed by Zhang et al. [12]. The temperature effects on bamboo fibers were examined and found that the bamboo fiber reinforced epoxy composite (BFREC) with $40 \%$ fiber volume fraction exhibited the highest tensile and flexural strength compared to polyester and vinyl ester composites [6]. The mechanical properties of bamboo were presented $[7,8]$ and specifically showing the behavior on fire [8].

Nanotechnology is a science and a technique of synthesizing materials, functional structures, and devices at the nanometer scale. Nanomaterials can be produced using two approaches, namely the bottom-up and top-down approaches. The bottom up approach is to start from the atoms or molecules that form the desired nanometer sized particles. In the topdown approach, bulk material is crushed in such a way so that the particle produced is in nano scale. The top-down approach can be done with ball milling technology, which the size reduction comes from the collision between the balls or the balls and container walls.

One of the problems that are still faced in developing nanomaterials with ball milling technology is efficiency. It takes a long time and low productivity. In addition, the resulting particles still have a relatively large size. The ball mill method takes between 8-10 hours. The resulting particles are between $250-475 \mu \mathrm{m}$ in size [13]. Supriyono et al. [14, 15] developed a new design of ball milling machine and studied the effect of cycle number and ball diameter on the final particle size and morphology of bamboo charcoal. The final particle sizes are in the range of $250 \mathrm{~nm}$ to $500 \mathrm{~nm}$.

With the same machine, Supriyono and Susilo [16] studied the effect of the empty space for the ball movement to the final particle size of bamboo charcoal. The study was conducted at machine rotation of $900 \mathrm{rpm}$ for 2 million cycles. The final particle sizes are in the range of $422 \mathrm{~nm}$ to $739 \mathrm{~nm}$ and there is no correlation in between empty space and the final particle size.

Nanoparticles are a very interesting study, because materials that are in nano size usually have particles with chemical or physical properties that are superior to bulk 
materials [17]. Two main things that make nanoparticles different from similar bulk materials [13]: (1) nano particles have much higher ratio between surface and volume when compared to similar particles in bulk. This makes the nanoparticles more reactive. Material reactivity is determined by the atoms on the surface, because only those atoms are in direct contact with other materials (2) when the particle size goes to the nanometer scale, the applicable physical law is dominated by the laws of quantum physics.

The current research reported in this paper investigated the particle properties of Bamboo leave charcoal resulted by ball milling. This research is similar to the work done in previous work [16], however this work used different material for being milled and further work was done to see the effect of the machine speed to the characteristics of resulted particles. This research used bamboo leaves charcoal which has high silica content instead of bamboo charcoal. As research by Karunakaran et al. [4], nano silica had shown better effect on the growth of crop plants.

This research works reported in this paper provided an added value to bamboo leaves as waste material due to the use of bamboo which is abundant in Indonesia.

\section{EXPERIMENT}

Bamboo leaves were processed to be charcoal by pyrolysis method. Pyrolysis is the thermochemical decomposition of organic matter through the process of heating without or little oxygen or other chemical reagents, where the raw material will undergo chemical structure breakdown into a gas phase. The effect of heating rate in pyrolysis is significant in producing charcoal [18]. In this work, about $3 \mathrm{~kg}$ of bamboo leaves is put in a reactor and heated at $300^{\circ} \mathrm{C}$ for 4 hours. Pyrolysis will produce charcoal, fuel gas, and bio-oil. In this research it ignores the last two products, so the process can be called extreme pyrolysis or carbonization.

The resulted charcoal was crushed manually in order to speed up the ball milling process. In this research, the particles produced from the manual crushing were then sieved with filter size of 200 mesh due to availability of the smallest filter. The particles passing the filter were proceeded for ball milling process.

The milling process was conducted in cylinder vial made from stainless steel. The milling elements was steel balls. The cylinder vial has dimension of $120 \mathrm{~mm}$ length and $1.6 \mathrm{inch}$ diameter. The ball has the diameter of $1 / 4$ inch. The particles passing the filter were then put together with the milling balls into cylinder vial. The cylinder vial was shaken to have ball collision for the size reduction. The cylinder vial and the steel balls are illustrated in Figure 1.
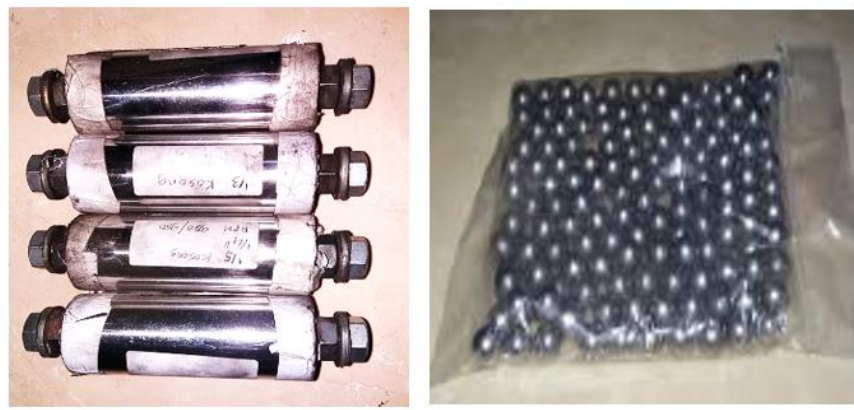

Figure 1. Cylinder vial (left) and steel balls (right)
There must be an empty space in the cylinder vial for the ball movement to collide. The emptier space of the vial volume is the more the balls to move. It gives higher kinetics energy to the balls individually. The first test in this work is to see the effect of empty space of the vial volume to the characteristics of the resulted particle. In this case, the shaker machine was operated at $1000 \mathrm{rpm}$ for 2 million cycles. In this work, the empty space in the vial was varied for $1 / 2,1 / 3,1 / 4$ and $1 / 5$ empty space of the vial volume.

Figure 2 is the detail of the ball milling machine used in this work. The machine consists of 6 components. The control unit is to control the speed of the driving motor, the duration of the operation, and automatic switch to turn off the device after certain duration of operation which is set. Some displays are on the control unit i.e. actual speed of the motor, cycle number (representing the duration of the operation), control speed button, control duration button and on-off switch. The actual speed of the motor is reduced by a reduction pulley with the ratio of $1: 3$. The connecting rod changes rotation motion of the pulley into translation motion of swing unit

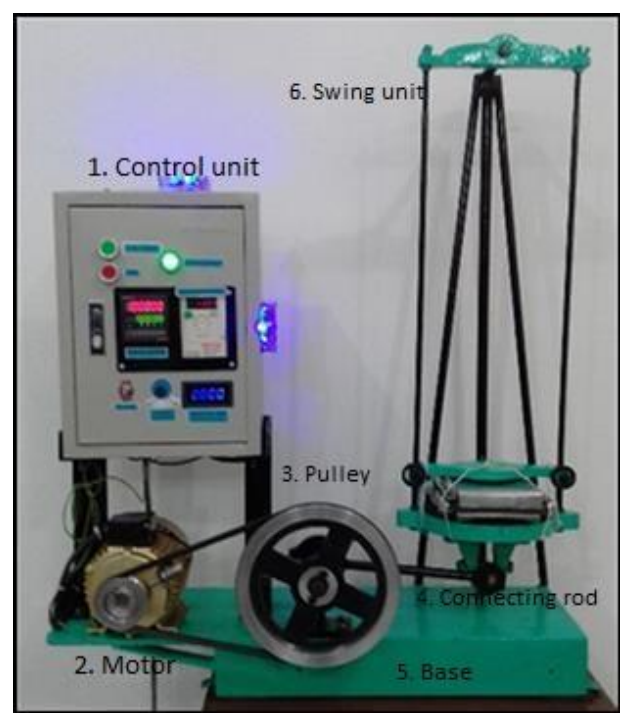

Figure 2. Shaker mill

For recording the results, the experiments were named according to the data of the empty space of vial volume, the dose of charcoal powder and ball, the total balls and the weight of the ball used in the vial. The classification name of vial number is shown in Table 1.

In order to measure the particle size, a Particle Size Analyzer (PSA) was used to have average of the particle size. Scanning electron microscope (SEM) and Energy Dispersive X-ray (EDX) had been used to have particle morphology and the element contents in the bamboo leaves charcoal.

Table 1. Content of vials

\begin{tabular}{cccccc}
\hline $\begin{array}{c}\text { No. } \\
\text { Vial }\end{array}$ & $\begin{array}{c}\text { Empty } \\
\text { space of } \\
\text { vial volume }\end{array}$ & $\begin{array}{c}\text { Dose } \\
\text { charcoal } \\
\text { powder }\end{array}$ & Ball & $\begin{array}{c}\text { Total } \\
\text { Ball }\end{array}$ & $\begin{array}{c}\text { Weight } \\
\text { Ball (gr) }\end{array}$ \\
\hline 1 & $1 / 2$ & $1 / 4$ & $1 / 4$ & 260 & 279.19 \\
2 & $1 / 3$ & $1 / 3$ & $1 / 3$ & 347 & 360.60 \\
3 & $1 / 4$ & $3 / 8$ & $3 / 8$ & 390 & 405.29 \\
4 & $1 / 5$ & $2 / 5$ & $2 / 5$ & 416 & 432.31 \\
\hline
\end{tabular}

The second test is to have the effect of the machine speed to the characteristics of the resulted particles. In this case, the 
machine is operated at $800 \mathrm{rpm}, 900 \mathrm{rpm}, 1100 \mathrm{rpm}$ for $1 / 5$ empty space and 0.25 -inch ball diameter. The more speed means the more energy for the balls to collide.

\section{RESULT AND DISCUSSION}

The results of particle size analyzer of the first test are shown in Table 2. It is shown that the increase in empty volume of the vial does not give any certain connection to the decrease of the particle size. The smallest particle with average size of $349.7 \mathrm{~nm}$ is resulted by $1 / 5$ empty space of the vial volume. The $1 / 8,5 / 32$, and $3 / 16$ empty space of the vial volume have average sizes of $588.4 \mathrm{~nm}, 414.7 \mathrm{~nm}$ and 442.8 nm respectively.

Table 2. PSA results of the first test

\begin{tabular}{cc}
\hline Empty space of the vial volume & Average particle size (nm) \\
\hline $1 / 2$ & 588.4 \\
$1 / 3$ & 414.7 \\
$1 / 4$ & 442.8 \\
$1 / 5$ & 349.7 \\
\hline
\end{tabular}

Table 3. PSA results of the second test

\begin{tabular}{cc}
\hline Machine speed (rpm) & Average particle size (nm) \\
\hline 800 & 557.1 \\
900 & 487.1 \\
1000 & 349.7 \\
1100 & 264.3 \\
\hline
\end{tabular}
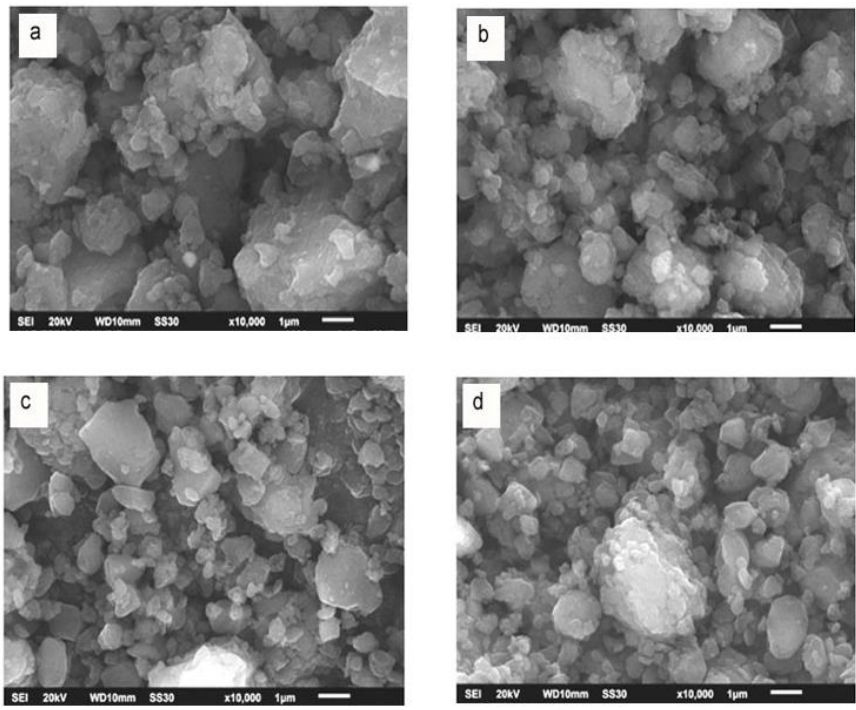

(a) 1/2 empty space of vial volume, (b) 1/3 empty space of vial volume, (c) 1/4 empty space of vial volume, (d) 1/5 empty space of vial volume

Figure 3. Results of SEM

In ball milling, impact and attrition are the main factor for the particle size reduction. The impact seems the dominant factor for coarser particle and the attrition is the reduction factor for fine particles.

Theoretically, impact or collision energy depends on the kinetic energy of the balls. The kinetic energy is determined by the speed and the mass of the balls. In this case, the emptier space of the vial does not increase the kinetic energy even though the balls move more freely. It can be seen that the less empty space tends to give smaller particle size. It is due to the higher mass of the milling ball that gives more kinetic energy to collide.

Table 3 shows the particle size analyzer of the second test. It can be seen that the more speed gives the smaller particle size. This is in line with the increase of the kinetic energy for the ball to collide. At the same duration of the milling process the reduction size rate of the higher speed is greater than the less speed. In this work the 1100 which is the highest speed $\mathrm{rpm}$ gives the highest size reduction rate producing the smallest average particle size of $264.3 \mathrm{~nm}$.

According to Chen at al. [19], the size reduction mechanism can be described as follows: materials are repeatedly crushed and broken at the time of the grinding process. Crashes occur in between the milling balls or the milling balls and the container wall. As the results of the high impacts energy from the crashes, the particles are severely deformed and produce a high density of dislocations and other structural defects.

The deformation and the dislocation of particles cause the continuous size reduction. The particles resulted in this work are not in standard of nanoparticle yet. According to Kumar et al. [20], nanoparticle is particle in the size of 1 to $100 \mathrm{~nm}$.

The PSA results are supported by SEM results displayed in Figure 3 and Figure 4. The magnification factor set in SEM was 10,000 times. Looking at the SEM results shown in Figure 3 and 4 , it is clear that particle size distribution of each test is not homogeny. A lot of particles are less than $1 \mu \mathrm{m}$, on the other hand there are particles that are more than $1 \mu \mathrm{m}$. It can be said that grinding limit in this work is not achieved yet. The grinding limit is the duration of milling process in which the increase of the milling time does not make further size reduction. In this work the milling time is represented by the cycles. It can be looked at the SEM results that the surface morphology of the particles for all tests is determined by crack mechanism.
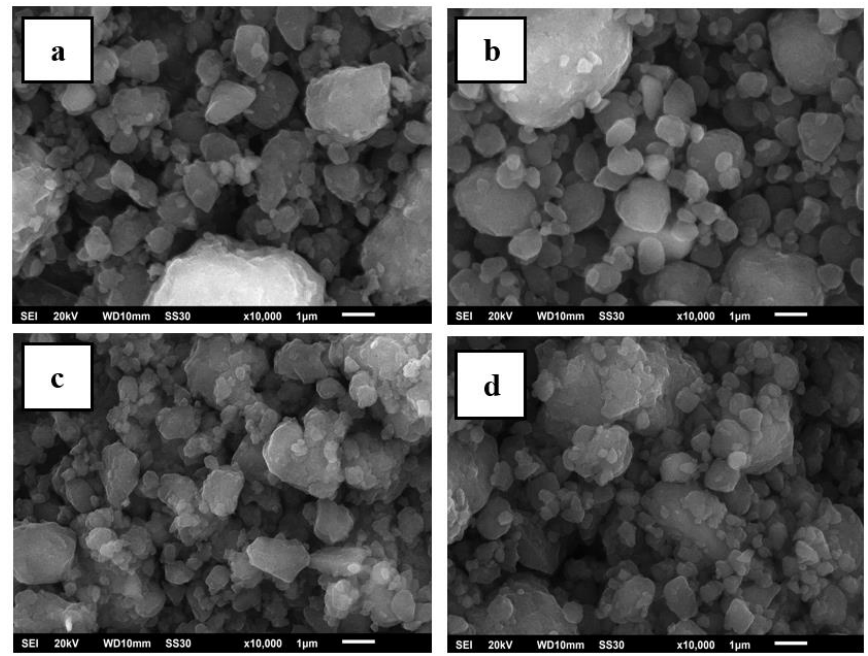

(a) speed of $800 \mathrm{rpm}$, (b) speed of $900 \mathrm{rpm}$,

(c) speed of $1000 \mathrm{rpm}$, (d) speed of $1100 \mathrm{rpm}$

Figure 4. Results of SEM

The results were supported by Eckert \& Börner [21] suggesting that the surface morphology of the particle produced by ball milling is subjected to some variables, for example the ball size and the milling speed. The milling speed is influenced by the motor speed.

The compositions of the bamboo leaves charcoal analyzed in EDX are listed in Table 4. These EDX elements results showing the complete composition of the bamboo leaves charcoal. It can be seen that the highest element is carbon 
which is more than $60 \%$ weight. The second highest element is silica which is more than $20 \%$ weight. The results are consistent even the data are taken from different cylinder vial with different content space.

Table 4. Composition of bamboo leaves charcoal

\begin{tabular}{ccccc}
\hline & \multicolumn{4}{c}{ Composition (wt\%) } \\
\cline { 2 - 5 } Element & $\begin{array}{c}\text { Empty } \\
\text { space of } \\
\mathbf{1 / 2} \text { vial } \\
\text { volume }\end{array}$ & $\begin{array}{c}\text { Empty } \\
\text { space of } \\
\mathbf{1 / 3} \text { vial } \\
\text { volume }\end{array}$ & $\begin{array}{c}\text { Empty } \\
\text { space of } \\
\mathbf{1 / 4} \text { vial } \\
\text { volume }\end{array}$ & $\begin{array}{c}\text { Empty } \\
\text { space of } \\
\mathbf{1 / 5} \text { vial } \\
\text { volume }\end{array}$ \\
\hline $\mathrm{C}$ & 67.21 & 66.14 & 67.09 & 68.47 \\
$\mathrm{MgO}$ & 0.66 & 0.66 & 0.66 & 0.66 \\
$\mathrm{Al} 2 \mathrm{O} 3$ & 1.02 & 1.02 & 1.02 & 1.01 \\
$\mathrm{SiO} 2$ & 24.09 & 21.39 & 23.19 & 22.59 \\
$\mathrm{SO} 3$ & 0.46 & 0.43 & 0.48 & 0.43 \\
$\mathrm{C} 1$ & 0.15 & 0.16 & 0.16 & 0.19 \\
$\mathrm{~K} 2 \mathrm{O}$ & 0.50 & 0.50 & 0.52 & 0.51 \\
$\mathrm{CaO}$ & 2.19 & 1.90 & 1.43 & 1.87 \\
$\mathrm{FeO}$ & 0.99 & 0.87 & 1.18 & 1.23 \\
$\mathrm{CuO}$ & 0.92 & 0.82 & 0.80 & 0.76 \\
$\mathrm{ZnO}$ & 1.10 & 1.15 & 1.10 & 1.22 \\
$\mathrm{ZrO} 2$ & 0.69 & 0.97 & 0.87 & 1.07 \\
\hline
\end{tabular}

\section{CONCLUSION}

Based on the results presented in this research, it can be stated that the variation of the empty space for ball movement does not give any influence on the final particle size. However, the emptier space means the more freely for the ball movement as a grinder, and this parameter influence the speed of grinding which influences the surface morphology of the final particle.

The highest element of the bamboo leaves charcoal is carbon and the second is silica. The compositions consist of more than $65 \%$ are carbon (C) element, $25 \%$ are Silica Oxide $\left(\mathrm{SiO}_{2}\right)$ and other $10 \%$ are various elements.

\section{ACKNOWLEDGMENT}

The authors would like to thank to Research Management Office of Universitas Muhammadiyah Surakarta for the financial support to conduct this research and publication.

\section{REFERENCES}

[1] Suhardiman, M. (2011). Kajian pengaruh penambahan serat bambu ori terhadap kuat tekan dan kuat tarik beton. Jurnal Teknik, 1(2): 88-95.

[2] Dransfield, S., Widjaja, E.A. (1995). Plant resources of South-East Asia. PROSEA.

[3] Amu, O.O., Adetuberu, A.A. (2010). Characteristics of bamboo leaf ash stabilization on lateritic soil in highway construction. International Journal of Engineering and Technology, 2(4): 212-219.

[4] Karunakaran, G., Suriyaprabha, R., Manivasakan, P., Yuvakkumar, R., Rajendran, V., Prabu, P., Kannan, N. (2013). Effect of nanosilica and silicon sources on plant growth promoting rhizobacteria, soil nutrients and maize seed germination. IET Nanobiotechnology, 7(3): 70-77. https://doi.org/10.1049/iet-nbt.2012.0048

[5] Mohd Joharudin, N.F., Abdul Latif, N., Mustapa, M.S., Mansor, M.N., Siswanto, W.A., Murugesan, J., Yusof, F.
(2019). Effect of amorphous silica by rice husk ash on physical properties and microstructures of recycled aluminium chip AA7075. Materialwissenschaft und Werkstofftechnik, 50(3): 283-288.

[6] Chin, S.C., Tee, K.F., Tong, F.S., Ong, H.R., Gimbun, J. (2020). Thermal and mechanical properties of bamboo fiber reinforced composites. Materials Today Communications, 23 : 100876. https://doi.org/10.1016/j.mtcomm.2019.100876

[7] Xu, M., Cui, Z., Tu, L., Xia, Q., Chen, Z. (2019). The effect of elevated temperatures on the mechanical properties of laminated bamboo. Construction and Building Materials, 226: 32-43. https://doi.org/10.1016/j.conbuildmat.2019.07.274

[8] Tanpichai, S., Witayakran, S., Srimarut, Y., Woraprayote, W., Malila, Y. (2019). Porosity, density and mechanical properties of the paper of steam exploded bamboo microfibers controlled by nano fibrillated cellulose. Journal of Materials Research and Technology, 8(4): 3612-3622. https://doi.org/10.1016/j.jmrt.2019.05.024

[9] Hai, L., Choi, E.S., Zhai, L., Panicker, P.S., Kim, J. (2020). Green nanocomposite made with chitin and bamboo nanofibers and its mechanical, thermal and biodegradable properties for food packaging. International Journal of Biological Macromolecules, 144 491-499. https://doi.org/10.1016/j.ijbiomac.2019.12.124

[10] Lam, S.S., Azwar, E., Peng, W., Tsang, Y.F., Ma, N.L., Liu, Z., Kwon, E.E. (2019). Cleaner conversion of bamboo into carbon fibre with favourable physicochemical and capacitive properties via microwave pyrolysis combining with solvent extraction and chemical impregnation. Journal of Cleaner Production, 236: 117692. https://doi.org/10.1016/j.jclepro.2019.117692

[11] Yusof, F.M., Wahab, N.A., Rahman, N.L.A., Kalam, A., Jumahat, A., Taib, C.F.M. (2019). Properties of treated bamboo fiber reinforced tapioca starch biodegradable composite. Materials Today: Proceedings, 16: 23672373. https://doi.org/10.1016/j.matpr.2019.06.140

[12] Zhang, X., Wang, X., Gao, Y., Ma, P. (2019). Fabrication of bamboo-structure hollow polyester monofilaments for extraordinary compression properties. Composite Structures, $\quad 230$ : 111423. https://doi.org/10.1016/j.compstruct.2019.111423

[13] Mikrajuddin, A., Yudistira, V., Nirmin, Khairurrijal, K. (2008). Review: Sintesis nanomaterial. Jurnal Nanosains \& Nanoteknologi, 1(2): 33-57.

[14] Supriyono, Ngafwan, Joharwan, J.W. (2018). The Effect of the cycle number on the product characteristics of shaker high energy ball milling to produce nano particle from bamboo charcoal. Advanced Science Letters, 24(12): 9054-9057. https://doi.org/10.1166/asl.2018.12082

[15] Supriyono, Ngafwan, Joharwan, J.W. (2018). The effect of the ball size on the product characteristics of shaker HEM to produce nano particle from bamboo charcoal. In Materials Science and Engineering Conference Series, 403(1): $\quad 012090 . \quad$ https://doi.org/10.1088/1757899X/403/1/012090

[16] Supriyono, S., Susilo, B. (2019). Characterization of bamboo tutul charcoal particle produced by high energy ball milling shaker type. Media Mesin: Majalah Teknik Mesin, 20(1): 43-48.

[17] Vestal, C.R., Zhang, Z.J. (2004). Magnetic spinel ferrite 
nanoparticles from microemulsion. Int. Journal Nanotechnol, 1(1): 240-263.

[18] Somerville, M., Deev, A. (2019). The effect of heating rate, particle size and gas flow on the yield of charcoal during the pyrolysis of radiata pine wood. Renewable Energy. https://doi.org/10.1016/j.renene.2019.11.036

[19] Chen, Y., Li, C.P., Chen, H., Chen, Y. (2006). Onedimensional nanomaterials synthesized using highenergy ball milling and annealing process. Science and Technology of Advanced Materials, 7(8): 839-846. https://doi.org/10.1016/j.stam.2006.11.014
[20] Kumar, A., Vlach, T., Laiblova, L., Hrouda, M., Kasal, B., Tywoniak, J., Hajek, P. (2016). Engineered bamboo scrimber: Influence of density on the mechanical and water absorption properties. Construction and Building Materials, (127):

815-827.

https://doi.org/10.1016/j.conbuildmat.2016.10.069

[21] Eckert, J., Börner, I. (1997). Nanostructure formation and properties of ball-milled NiAl intermetallic compound. Materials Science and Engineering: A, 239: 619-624. https://doi.org/10.1016/S0921-5093(97)00639-4 